\title{
Family Traditional Bakery Business Sustainability: An Analysis on its Contributing Success Factors
}

Norsyahidatun Naim Misran, Mohd. Shazali Md. Sharif, Mazni Saad, Shahrim Ab Karim, Alina Syuhaida Ramly

To Link this Article: http://dx.doi.org/10.6007/IJARBSS/v11-i16/11232

DOI:10.6007/IJARBSS/v11-i16/11232

Received: 16 July 2021, Revised: 20 August 2021, Accepted: 30 August 2021

Published Online: 19 September 2021

In-Text Citation: (Misran et al., 2021)

To Cite this Article: Misran, N. N., Sharif, M. S. M., Saad, M., Karim, S. A., \& Ramly, A. S. (2021). Family Traditional Bakery Business Sustainability: An Analysis on its Contributing Success Factors. International Journal of Academic Research in Business and Social Sciences, 11(9), 244-260.

Copyright: (C) 2021 The Author(s)

Published by Human Resource Management Academic Research Society (www.hrmars.com) This article is published under the Creative Commons Attribution (CC BY 4.0) license. Anyone may reproduce, distribute, translate and create derivative works of this article (for both commercial and non-commercial purposes), subject to full attribution to the original publication and authors. The full terms of this license may be seen at: http://creativecommons.org/licences/by/4.0/legalcode

Special Issue Title: Contemporary Issues in Tourism and Hospitality industry, 2021, Pg. 244 - 260

Full Terms \& Conditions of access and use can be found at http://hrmars.com/index.php/pages/detail/publication-ethics 


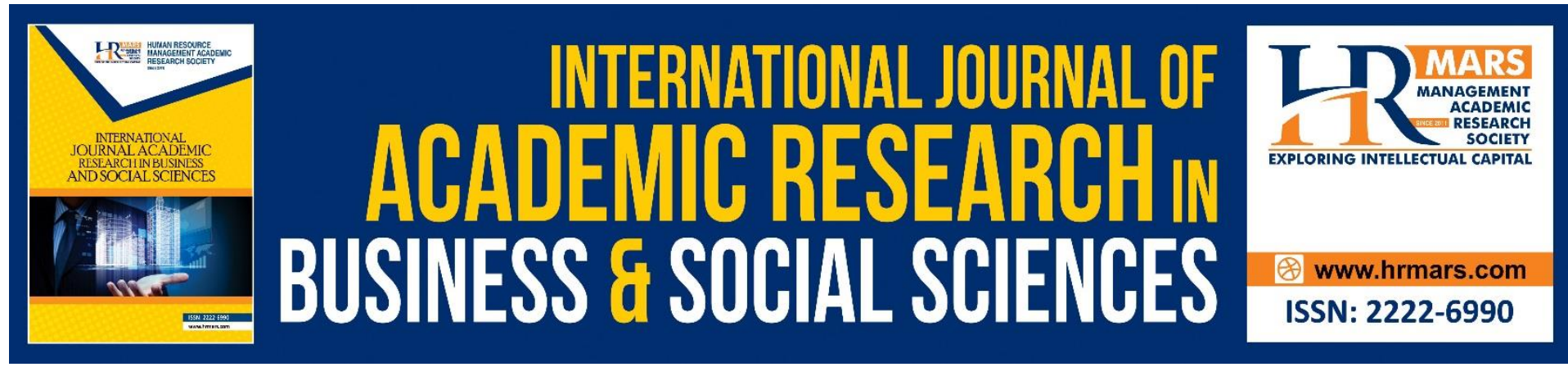

\title{
Family Traditional Bakery Business Sustainability: An Analysis on its Contributing Success Factors
}

\author{
Norsyahidatun Naim Misran ${ }^{1}$, Mohd. Shazali Md. Sharif², Mazni \\ Saad $^{3}$, Shahrim Ab Karim ${ }^{4}$, Alina Syuhaida Ramly² \\ ${ }^{1}$ Department of Culinary Arts, School of Hospitality and Tourism, Kolej Yayasan Pelajaran \\ Johor, 81000 Kulai, Johor Malaysia, ${ }^{2}$ Department of Culinary Arts and Gastronomy, Faculty of \\ Hotel and Tourism Management, Universiti Teknologi MARA, Kampus Puncak Alam, 42300 \\ Selangor Malaysia, ${ }^{3}$ Department of Tourism, Kulliyyah of Languages and Management \\ International Islamic University Malaysia, Edu Hub Pagoh 84600, Johor Malaysia, \\ ${ }^{4}$ Department of Food Service and Management, Faculty of Food Science and Technology \\ Universiti Putra Malaysia (UPM), Serdang, 43400 Selangor, Malaysia \\ Email: shazali@uitm.edu.my
}

\begin{abstract}
The waves of civilization, industrialization, technological innovations, economic growth and increasing welfare of people have undoubtedly altered or changed the traditional food culture, including the traditional food products. Some might argue that the traditional foods products are slightly over ruined by the modern foods that seem to be more attractive and trendier. Whether this connotation holds true is not known. This paper attempted to identify the factors that affect the continuation of the family traditional food business. It mainly focused on Salahuddin Bakery located in Johor Baharu that offers their family traditional bakery production. Salahuddin Bakery has been operating for more than 80 years since 1937 . The ethnographic technique through observation approach was undertaken for seven days. A narrative analysis approach was applied in reporting the findings. Results revealed that five main factors led the bakery to continuously sustain itself. Premise, products, equipment, material, customer and knowledge transfer were the factors identified. Although some alterations were made in line with the modernisation, it did not involve the recipes, which were part of their family culture practice that has remained up to the fourth generation. In this sense, preserving and transferring the family food and business knowledge is one of the essential factors in determining the successful sustainability of the traditional family food business.
\end{abstract}

Keywords: Traditional Food, Traditional Food Business, Bakery Business, Sustainability

\section{Introduction}

Since ancient times, food invention and production have existed in our civilisations due to the human need for nutrients. Food is the source of nutrition for humans and it plays a wide range of roles and complexities in everyday life (Ma, 2015). Almerico (2014) postulated that people's food choices, either as individuals or as a group, may expose beliefs, interests, 
background knowledge, perceptions, and personalities in which the social and cultural environment greatly influences it. Presently, food tourism has emerged, emphasising the development of food within tourism product offerings, as food can be a draw to a destination (Moginon et al., 2012). Moreover, food production has also been based on traditional knowledge passed down from one generation to the next. This knowledge can be maintained through regular practice and knowledge sharing between senior and younger generations in the community (Muhammad et al., 2015; Saad et al., 2021). For instance, family food tradition in which food is produced can be conserved and progressed along with the social and technological evolution if nurtured or applied through knowledge transmission with regular practice. Furthermore, that knowledge and experience would open opportunities for traditional food to be commercialised. Therefore, this study attempted to identify and tell apart the uniqueness of traditional food products, particularly at Salahuddin Bakery in Johor.

\section{Literature Review \\ Traditional Food}

In ordinary language, scholars commonly refer to tradition as a long-term and continuing element in the practices. Traditional often connects with activities and products created by earlier generations, who first invented or created them (Kwik, 2008). European Union (2007) refers to food that has been for multiple generations in the given region or locality. Trichopoulou et al (2007) asserted that traditional food expresses one's culture, history, and lifestyle, besides influencing contemporary dietary patterns. European Union (2007) discovered that many traditional foods have been long-revered, even though their historical origins have not been established. According to Bertozzi (1998), traditional food products represent a group, belong to space, link to a culture, and facilitate cooperation for those who continuously work in that area (Jordana, 2000).

An improved food definition incorporates traditional ingredients, composition, and production methods for traditional food components (Trichopoulou et al., 2007). From the various definitions of traditional food, the most relevant definition to this research context is the one given by Albayrak and Gunes (2010). The foods can usually be passed down from one generation to another. According to the gastronomic heritage, the transmission process is made accurately in a specific way, with little or no processing or manipulation, distinguished and known because of its sensory properties and associated with a specific local area, region or country (Albayrak \& Gunes, 2010).

\section{The Role of Traditional Food in the Society}

The central role of food, including the traditional one in human daily life and culture, is far beyond exploring cooking and consumption, as Counihan and Van Esterik (2008) argued. Different people from different places with different cultures perform different food preparation and consumption patterns that reflect the character of their culture (Rearick, 2009). Many scholars associate traditional foods with an actor's behaviour, which involves the preparation, presentation, and consumption characterised by individuals and society (Gold, 2007; Welch \& Scarry, 1995; Williams-Forson, 2007). Traditional food performs as a point of and for social contact (Rearick, 2009) which strengthens social bonds while the preparation, serving, and eating of foods often supply a space for interaction or open up communication lines (Counihan \& Van Esterik, 2012). O'Connor (2008) expounded the possibility of a family structure being developed based on parents sharing foods with their 
offspring. Traditional food and its practices bind individuals in the family together by sharing it, enjoying each other's company, keeping familial ties strong (Debevec \& Tivadar, 2006) and even binds people together in many parts of the world (Di Piazza et al., 2004).

Food and communication not only strengthen communication between families but encourage communication between people in the communities. Muhammad et al (2013) revealed that cultural and social feasts organised by the communities like wedding ceremonies and thanksgiving can indirectly foster relationships among the local communities through their involvement in preparing traditional foods in the events that generations have practised. Some noted that food could not be separated from the events (Albayrak \& Gunes, 2010; Muhammad et al., 2013). This can especially be seen on grand and special occasions whereby traditional food has more impact on society (Muhammad et al., 2013).

Through its preparation and consumption, food symbolises and marks the class structure of individual or society as different classes of society used food as a symbolic way to differentiate themselves through appreciation of etiquette and aesthetic factors (Crotty, 2004). In this sense, the wealthy group could afford to host feasts and banquets lavishly than the poor. In addition, Rearick (2009) and O'Connor (2008) highlighted that traditional food functions as a transmitter of cultural knowledge. The elements of traditional foodways, which refers to preparation and consumption, traditions and histories as explained by Gutierrez (1999), are mostly passed down from generation to generation and informally transmitted through oral and demonstration. For instance, during the food preparation, the knowledge is passed from mother to daughter where communication occurs between different generations and ages while the history of foods is passed verbally and practically. Traditional food is also acting as a social mediator among the generation (Gutierrez, 1999). New England Clambake is one of the examples. The practices of traditional food products have long been the tradition of family and community. The practices were passed down from the Natives Americans to the colonists and further to their descendants.

Food is often associated with religious or cultural ceremonial and special occasions; thus, foods prepared represent meaning to specific groups, societies, or nations. Certain foods are long-listed as requested ingredients and other requirements such as eggs, lime juice and so on in the traditional medication which is believed to dispel spiritual disorders. Different people who live in different countries have different customs in consuming and utilising the foods, and serving it. Food permits a person to perform a specific identity and belief by preparing, cooking, serving and consuming it (Rearick, 2009).

\section{The Progress, Trends and Contravene of Traditional Food}

The progress in the context of this study is referred to as dealing with traditional food, which is likely to implicate the acceptance and its relevance in this era. As found by Almli et al (2011), traditional food has a positive general image in most of the European countries and plays an important role in their local identity, which involves transferring the cultural heritage for future generations. The European Union (2007) reported that the European traditional food products have received increasing policy support in terms of protection, such as Protected Designation of Origin (PDO), Protected Geographical Indication (PGI), or Traditional Specialties Guaranteed (TSG) to a food product (Amli et al., 2011). These collective trademarks allow the food producers to commercialise and promote traditional food products and differentiate 
them in the market. As a result, traditional foods have become increasingly attractive from an industry perspective, especially for small and medium-sized enterprises in the European Nations (Pieniak et al., 2009). In this sense, traditional foods seem to be consumed in a specific area and can now be exported globally due to commercialisation.

Regarding the traditional food trend, many scholars noted that the communities acknowledged and perceived the local traditional foods as high quality and safe to consume and more sustainable for cultural identity and ethnocentrism. In many countries, the demand for traditional foods is increasing each year, which has created a favourable demand for its products, especially among small and middle-sized enterprises (Albayrak \& Gunes, 2010). Several studies found that traditional foods are healthier products that last longer due to the domestic technology process (Egeland et al., 2009; Yohannes, 2009).

As traditional food is on a continuing journey, there is an obvious concern on some of its practices, particularly on the preparation method and originality of the ingredients that modern practitioners slightly alter. Scholars argue that although it is small and seemingly unimportant, the alteration may result from significant failures toward the originality and authenticity of traditional food itself. The increased interest with the lack of the available document comes to a danger that people in the correct methods may not prepare traditional foods or that the contemporary adaptations of traditional techniques may work against practices that had produced safe food for centuries (Whyte et al., 2001).

Despite the above notion, most ethnic foods, especially among native populations, are still preserved with no or fewer commercialisation aspects. Taking one example, traditional food prominently features ethnic community's identity in Canada (Egeland et al., 2009). For the Inuit community, as one of the ethnic communities in Canada, the hunting, harvesting and sharing of the traditional food provided social cohesion and ensured the survival of the traditional food products. Egeland et al. (2009) denoted that sharing in hunting, harvesting, and preparing food during the community feasts represents another avenue in which traditional food systems can indirectly promote health and well-being among indigenous people in Canada.

\section{Research Method}

The ethnographic technique through observation approach was undertaken in this study to tap on the uniqueness of the family traditional bakeries products offered by Salahuddin Bakery. Ethnography has successfully tapped the behaviour of the respondents in many studies such as Jeinie et al (2017); Sharif et al (2016, 2017, 2018). The observation process took place for seven days (Monday till Sunday) for six hours. The six hours were spent exploring the bakery shop, the range of product produced, equipment and raw materials used, customer response, and sustainability factors by observing, writing notes, and taking pictures. The observation emphasised finding factors that affected the family traditional foods business to be able to sustain for more than 80 years. For data collection, purposive sampling was applied to obtain some inside story of Salahuddin Bakery from their regular and familiar customers who have started being their customers since teenagers and now they are in their early seventies Besides the customers, Salahuddin family members were also interviewed to acquire information on the history of the family bakery business. At the initial stage, the approach used in the process was chronicled in a logbook. The observation was also infused 
by taking pictures to allow the snaps used as evidence of reporting in which narrative analysis was applied.

\section{Result and Analysis}

It is interesting to be precise that certain things remain unchanged despite rapid development that has happened. For instance, Salahuddin Bakery, a family traditional food business located at Jalan Dhoby, Johor Bahru, has proven that retaining old elements in the family heritage business is still the main attraction factor among the, especially the regular customers. Results from the observational studies conducted found that the factors that affect the sustainability of this bakery shop were due to various aspects. Premise, products, equipment, raw material, customer and knowledge transfer were the factors identified which contributed to its sustainability.

\section{Premise}

The location of Salahuddin Bakery is one of the oldest town areas in Johor Bahru city. The shop area was operational in 1937, so the design of the building looks old and classic even though the design of the shop building was considered sophisticated. The bakery is located near Jalan Dhoby in downtown Johor Bahru. The area is well known for its hipster cafes, traditional Chinese restaurants and classic bakeries. It is a hotspot for Singaporean visitors. Thus, it is not surprising if it has a rustic atmosphere. Even so, the natural state of Salahuddin Bakery has become an attraction to fans of heritage buildings and rustic atmosphere who have witnessed the relics of various secrets and memories. This old shop building is becoming more significant with a bakery whose lifespan is as old as the shop premise, 84 years old. It is considered one of the most iconic shops at Dhoby Street and the entire Johor Bahru city. It is located right in the heart of Johor Bahru old town. Although the condition of the shop premise does not look like a bakery shop and its appearance is gloomy as it ages, as shown in Figure 1, it is still a favourite and popular bakery for the local community and foreign tourists as well.

When entering the interior of the bakery premise, it is like being in a museum that portrays many picture frames that can tell their own story as it displays the earliest individuals who operate this bakery to the present one. It clearly illustrates that this traditional bakery has gone through various eras and challenges in maintaining significance and sustainability while providing memories and joyfulness through their bakery products for generations. Observing all the pictures displayed in this classic bakery shop has indirectly become an attraction for childhood customers to return to the bakery and recall the memory while growing with the bakery. One of the visitors stated that he visited the bakery as early as seven (7) years old in which he came with his late father. Now he is 65 years old and lives in Selangor but he felt excited and astonished to see this bakery has continued to operate at the exact location and premise that witnessed so many memories. Figure 1 shows the view and interior decoration of the 84-year-old family run-business, Salahuddin Bakery, located at No. 26, Jalan Dhoby, Johor Bahru. 


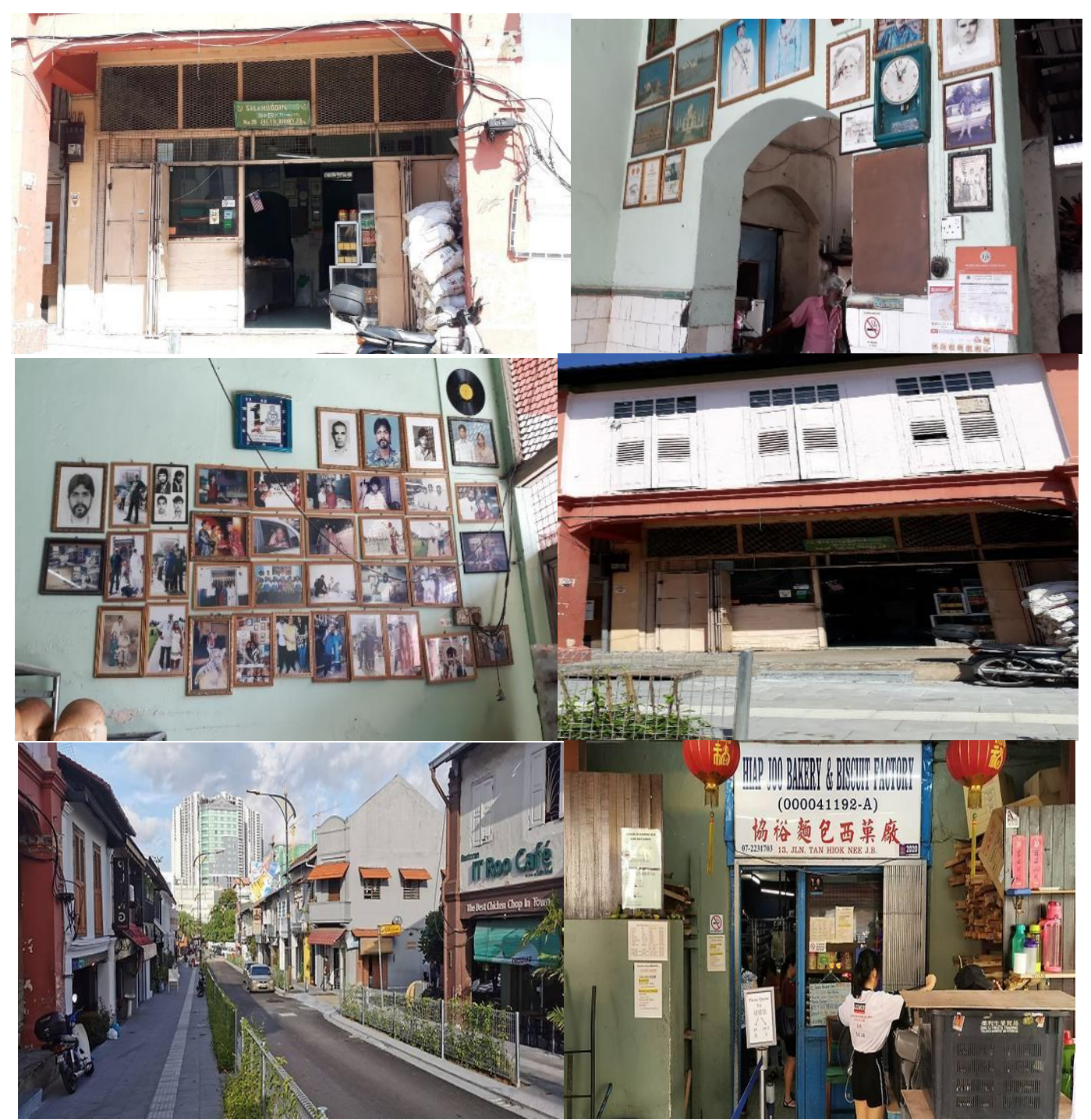

Figure 1: Street of Johor Bahru Old Town where Premise of Salahuddin Bakery is located

\section{The Bakery Products}

Salahuddin Bakery makes a wide range of old-style cakes, bread, pastries, muffins, and puffs baked in an old wood-fired oven. There are wide selections of traditional bread produced by Salahuddin Bakery. Among the top products available are triangular curry puffs with various fillings such as sardines, chicken and mutton. The shells of Salahuddin's curry puffs are crispy and flaky, with a woody aroma. Bits of the layered flaky crusts fall off as it is being bitten into the curry puff. The rounded insides are bulging with generous fillings. The shell and fillings taste are spicy and fleetingly pungent to the nose. The selling price of the curry puff ranges from RM2 to RM3. Besides famous curry puffs, Salahuddin also produces baked bread loaf (unsliced sandwich loaf), popularly known as 'Roti Benggali', which is available with plain white and wheat grains where the recipes were originally from South India. The selling price of 'Roti Benggali' is only RM2. Other than regular, the bakery also produces dried sugar and butter bread, raisin bread, and various kinds of buns, available with various fillings like shredded coconut bun, kaya bun, and red bean bun. The bakery products are displayed like the old times. The price range for all items in Salahuddin Bakery is very reasonable compared to other bakery shops around that town. For instance, six pieces of coconut buns are priced at RM3.50 only per packet. Another classic and popular product produced in this bakery is cream horn, a 
puff pastry shaped like a horn filled with white cream. Figure 2 shows various bread and pastries being laid out on the table for the customers to select and purchase.
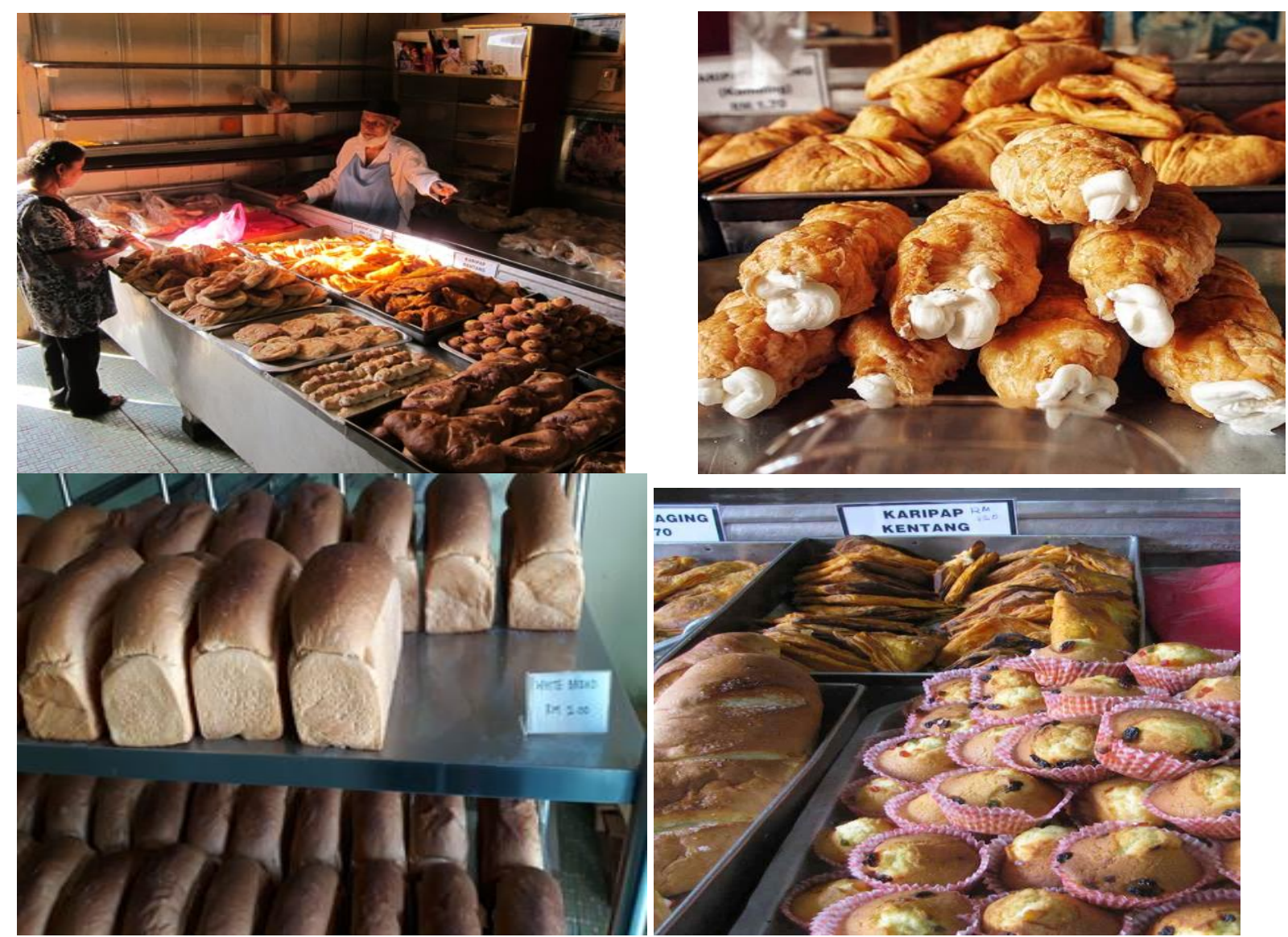

Figure 2 . The various product ranges and how they are arranged.

Offering a wide selection of bread products at affordable prices has made this bakery continue to stand out despite having to compete with more sophisticated and modern bakery shops. The selection of bread products on offer is also the same products offered over 80 years ago. A regular customer of this bakery explained that the taste of the bread he bought was the same as the taste he had bought 60 years ago. He also clarified that the bakery had several times tried to promote a new product; however, it just lasted for a few months. It indicated that the bakery products produced by Salahuddin Bakery are composed of the same bread products produced since the beginning of their operation in 1937. It also proved that the heritage products of the Salahuddin family are still popular among its customers. This has indirectly contributed to the survival of this bakery in business operation.

\section{Equipment}

Salahuddin bakery is one of the oldest bakeries in Johor Bahru old town that endure the ancient ways of charcoal and wood fire oven by classically baking their bread since 1937 from their great grandfathers who started establishing this bakery shop after a few years they arrived from India. The result based on the observation showed that the area of the firewood oven is equal to half of the standard room area, one hundred square feet. The Oven Room, which is over 80 years old, can bake as many as 32 trays of bread at once. This classic oven remains because this old stove emits an aroma that can evoke the desire of customers to keep repeating as bread buyers at the bakery. There is no denying that it is like being in a sauna 
room when we are in the oven room due to the hot heat coming out of the classic oven. The firewood oven is still well operating and maintained due to the low maintenance cost compared to electric oven. It is only necessary to replace the broken clay bricks and remove wood and charcoal ash after a few burning sessions or approximately once a week. The most important thing is the aroma produced from firewood and charcoal, which gives a unique flavour to the bread products produced by Salahuddin Bakery.

According to Rahim Khan, the son owner revealed that the production of bread in this shop has also undergone various improvement efforts, especially in terms of increasing productivity and quality of bread produced. Among them is the use of a bread mixing machine, which makes the preparation of bread now more manageable than before. This is due to the availability of technological equipment such as bread mixers. In the past, bread was kneaded by hand. Therefore, its production is not too much. Salahuddin Bakery can produce a wide selection of bread using at least $50-100 \mathrm{~kg}$ of flour per day. A bread mixer can also minimise preparation time, and the desired level of softness can be adjusted. However, there is a difference in bread texture compared to kneading by hand and using a machine. Undeniably, the sustainability of this bakery has been supported by modern equipment in line with technological advances in increasing the productivity of their bread production. Figure 3 demonstrates the main equipment used by this family traditional food business in preparing their food products. 


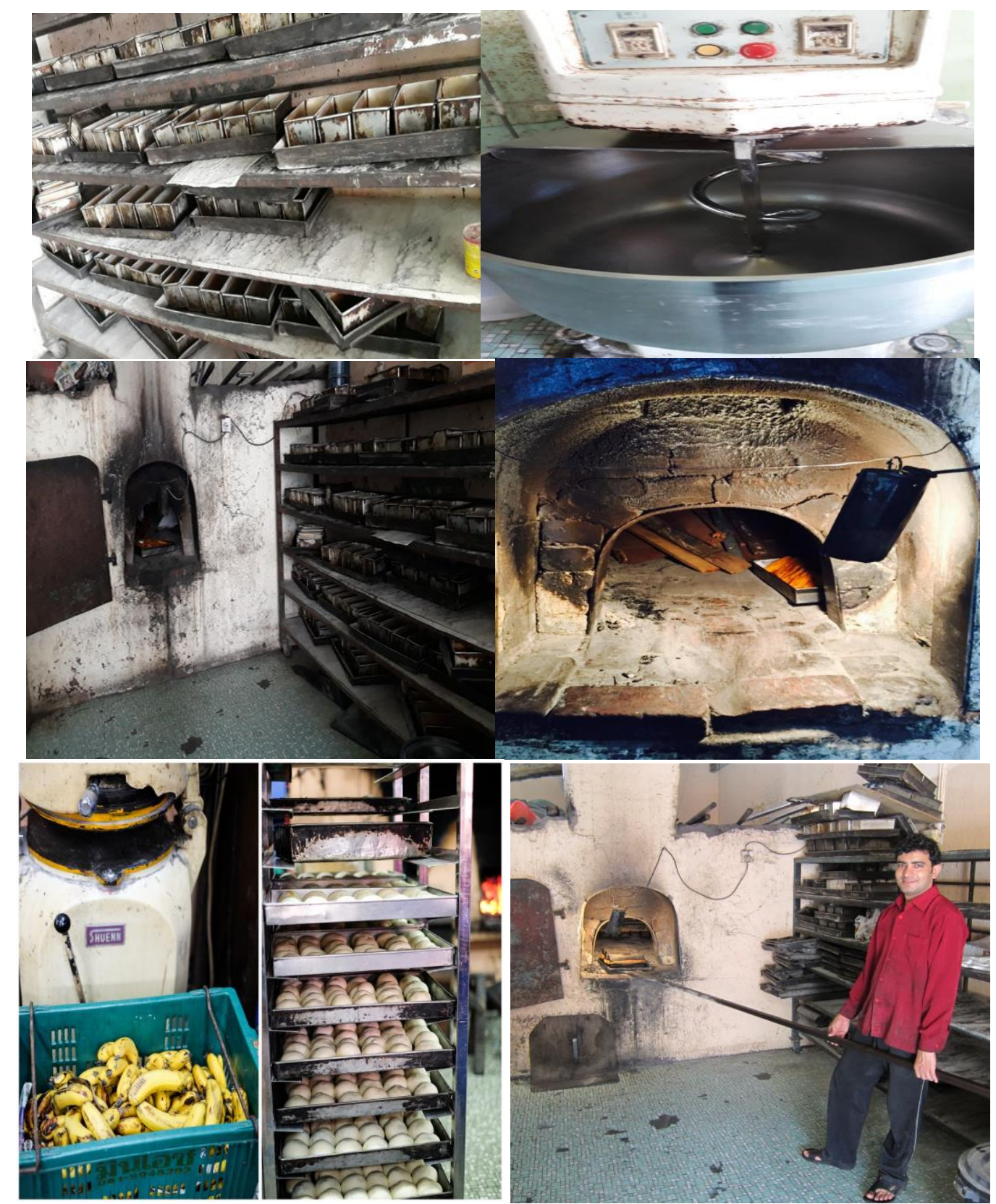

Figure 3. The main equipment used in the product preparation process.

\section{Raw Materials}

In terms of using raw materials in producing bread for this bakery, the priority is that it must be from a halal source and the material does not harm its users, especially when it involves chemical ingredients to obtain a well expanded and fluffy texture. Most of the bread fillings are made from scratch to ensure the quality and taste of their bread products. For example, the popular coconut bread uses homemade coconut filling instead of using ready-made or existing fillings from the market and other fillings such as red bean and curry filling prepared using the family tradition recipes since 1937. Most of the ingredients used are locally sourced products such as flour, margarine and potatoes. He also stressed that they would not use any food additives, preservatives, and food colouring to prepare their products. If he wanted to add some colour to his product, such as curry puff, he would use turmeric as an alternative which would give the food an original colour. Figure 4 exposes several basic ingredients used to make bread and pastries products in Salahuddin Bakery. 


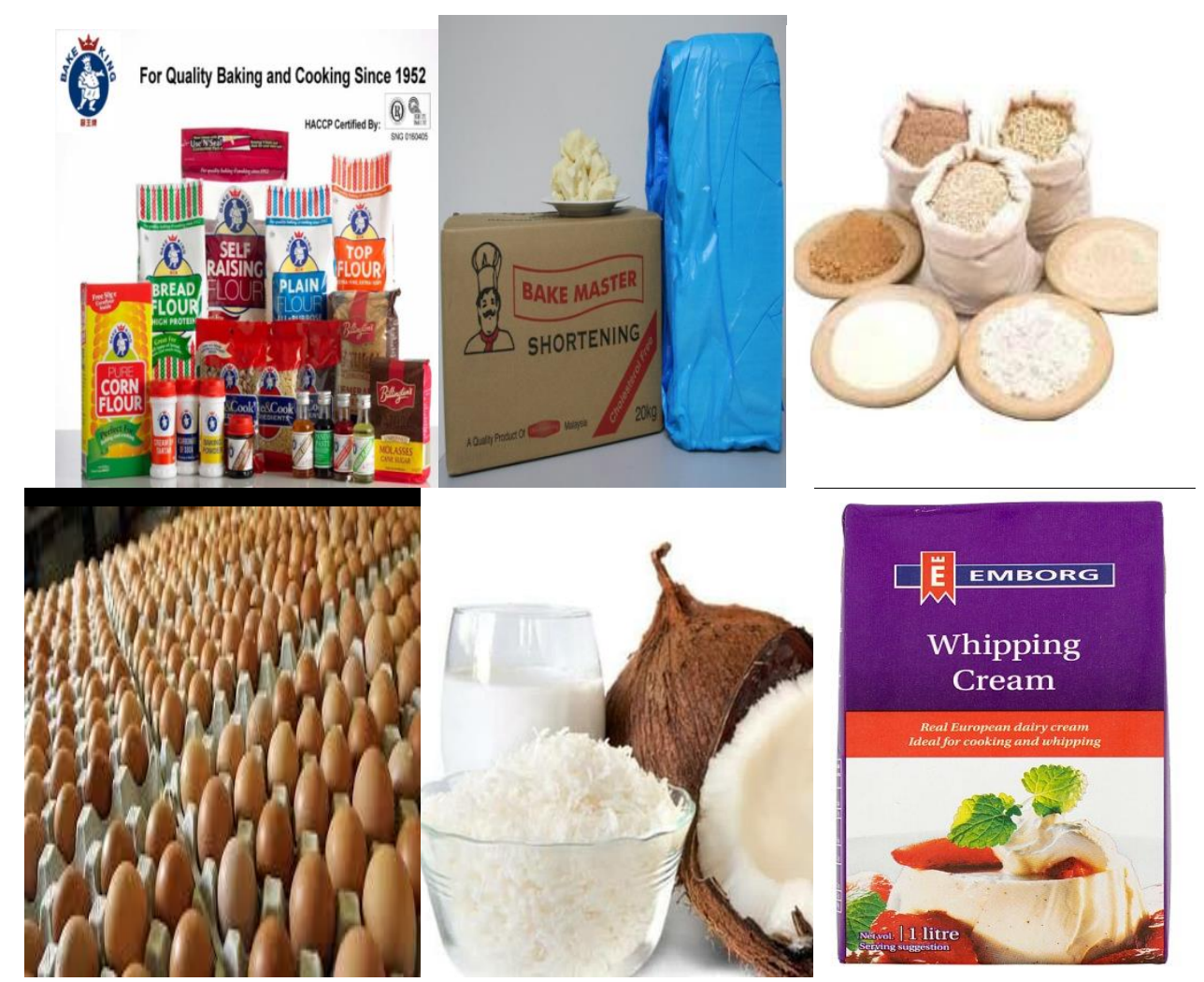

Figure 4. Types of raw materials used.

\section{Customer}

The entire crowd's favourite Salahuddin freshly baked bread has gained its name because it is cooked in an old room-sized coal-fired oven that has been used since they began the business. The observation carried out found that the customers of this bakery come from various backgrounds regardless of age, race, descent and standard of living. Their regular customers do not only come from Johor but some also come from Melaka and Singapore. This does not include tourists from all over Malaysia and abroad who are willing to come just to taste the various breads produced by Salahuddin Bakery which are delicious and baked with a firewood oven.

Some customers who have been interviewed stated that some of the reasons they always continue to buy bread at Salahuddin Bakery were due to the unique taste of bread, reasonable price, the same product quality even though it has existed for decades and finally it brings back memories to their older customers. For instance, Encik Azman, 50, has been a regular customer of this shop for more than twenty years. He claimed that he first bought bread from this bakery when he was little. On the other hand, Hajah Nafisah, who is in her 70s today, stated that the taste of the bread is unique, and she could not get the right taste from other bakeries. Some of the tourists interviewed stated that they knew about this bakery through their friend's blog post that they read before visiting Malaysia. They felt that this bakery is unique and interesting which needs to be maintained and inherited by Salahuddin's family members. Figure 5 demonstrates the shopping activities by the regular customers of this traditional bakery shop. 


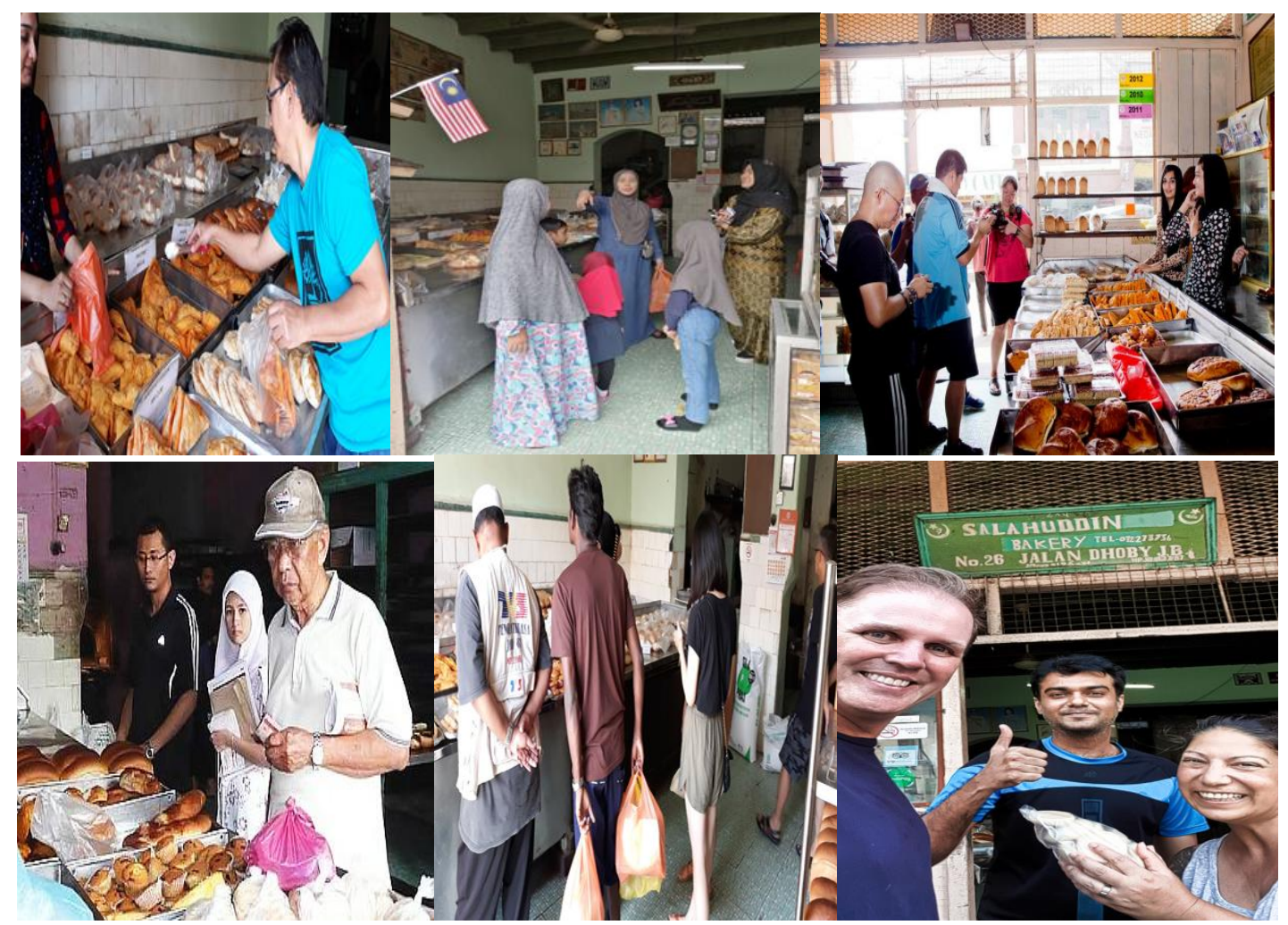

Figure 5. Some of the regular customers at Salahuddin Bakery.

\section{Knowledge Transfer}

The current owner is the fourth generation, Salahuddin Shamsul who is helped by his 31-yearold son, Rahim Khan and his 28-year-old daughter, Nesa. Previously, this family business was developed by his ancestor, a baker named Syariff Mohamed Mahku, 12 years after he arrived from New Delhi. Salahuddin inherited the business from his late father Shamsul Haq about 16 years ago, and this traditional bakery shop has been operating for more than 80 years. Salahuddin believed that this traditional family business could be sustained if his children inherited it. The recipe was passed down from one generation to the next and has become a culinary heritage in his family. He added that the business was managed among his family members by each of them taking turns to manage the counter. Based on the observation, Nesa is in charge at the counter from the early morning at 6 am until $12 \mathrm{pm}$. Then, the father comes by to take his turn until $2 \mathrm{pm}$. From $2 \mathrm{pm}$ until $6 \mathrm{pm}$, the bakery shop is handled by her brother, Rahim Khan. The preparation starts at $11 \mathrm{pm}$ by ensuring that all products are readily done before 6 o'clock in the morning. This work schedule is rotated for more than 80 years. These evidences showed that all family members have given their full dedication in running their traditional foods business.

The result of the interviews conducted on the heirs of Salahuddin bakery clearly showed that knowledge transfer is the key to the sustainability of this family heritage business. This is further strengthened by the use of recipes inherited by the first generation to make the taste of the bakery's bread remain the same. This has been confirmed by many regular customers who have been interviewed. Although they use the same recipe, it does not prevent them from using modern equipment such as mixers to improve the production and quality of their bread. This clearly shows that the combination of traditional recipes does not prevent the use of modern equipment to increase the productivity of this family heritage business. 


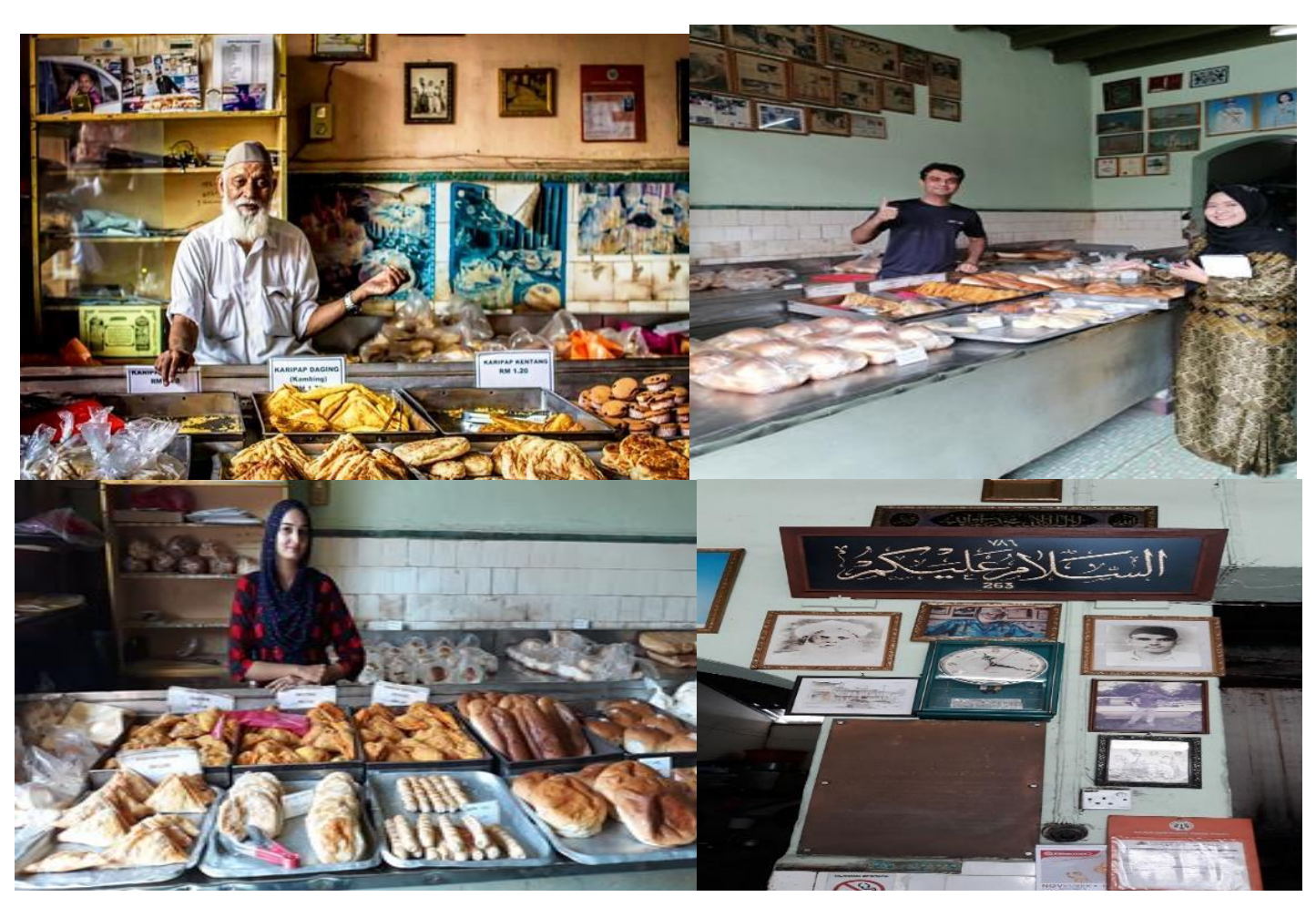

Figure 6 . The owner takes turns with his son and daughter in managing the store.

\section{Discussion}

This paper attempts to articulate the uniqueness and factors that affect the continuation of the business for generations by a family who migrated to Johor Malaysia for the last eighty years that has been offering their family traditional food, bakery-based products originated in India. Figure 7 visually illustrates the factors that affect the continuation of a family traditional food business. The narrative analysis based on the observation activities reports important information related to the factors that affect the continuation of a traditional family food business. Premise, products, equipment, material, customer and knowledge transfer are the factors identified. In this context of the study, the premise is closely related to the retention of the location of this bakery, which has been in operation for more than 80 years. This area is also known as Johor Bahru Old Town. It has indirectly made the street, location, and bakery a heritage premise that stores and witnesses the various histories passed and experienced by the family of this bakery trader and the surrounding community. The retention of the interior decoration of this bakery that still maintains the old way which looks rustic makes it more unique and attractive. This historical factor has made the bakery continue to remain visited. In terms of products, it clearly shows that this bakery offers a variety of bread, including those with fillings and curry puffs that are always in high demand. What is interesting here is that some of the bread produced has been offered since 1937. Among the reasons why Salahuddin Bakery's bread product is popular are due to its unique taste and aroma because it is baked using a firewood and charcoal oven. What is even more interesting is that it offers a very affordable price. Concerning equipment, among the traditional equipment that is still maintained in the operation of this bakery is firewood and charcoal oven, which is the same age as the bakery established in 1937 . The use of such an oven is rarely practised by bakery traders nowadays. The quality and aroma of the bread produced from this old oven is the main factor in maintaining baking all these bakery bread products. The operation of this bakery also 
goes forward by using modern equipment such as bread mixers. The usage of this machine has helped to increase the productivity of bread while saving time and manpower. This is in line with Muhamad et al. (2013) which noted that modernisation through technology advancement simplified the complex cooking procedures. This clearly shows that modern equipment can also play a role in maintaining and enhancing a family heritage product produced by the Salahuddin family.

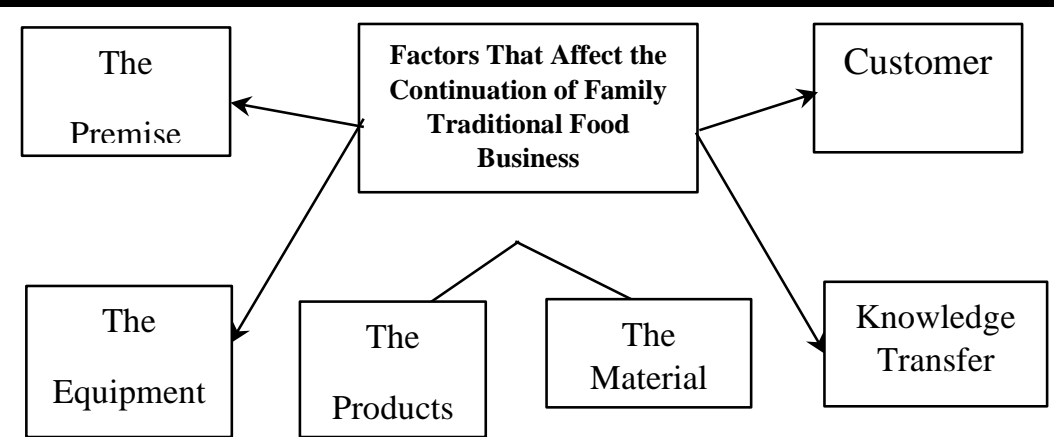

Figure 7: Visual illustration on the factors that affect the continuation of family traditional food business.

Another factor is material as it plays an important role in the bread production of Salahuddin Bakery. Among the preferred features in using raw materials for the production of bread is that they must come from halal and clean sources. This is because they are Muslims and most of their customers are Muslims as well. It has become the responsibility of this family to produce good quality products that are halal and clean. The bakery also does not use artificial chemicals and food colouring to maintain the nutritional value of the bread produced. This can be indirectly proven by the use of turmeric powder to obtain yellow colour and chilli powder for red colour. To maintain the authenticity of the bread filling, they process it from scratch to ensure the raw source of material rather than using a ready-made filling. Here it is clear that the use of raw materials as well as producing their own bread and puff fillings contribute to the continuity of their family's traditional bread business. In terms of customer, Salahudin Bakery has clients from various backgrounds regardless of age, religion, rank, and race. Among its main customers are the local communities, old customers who have migrated to other states and those over the age of sixty who are primarily Singaporeans.

One of the main reasons for their purchase is the unique taste of the bread baked using a firewood and charcoal oven while offering a reasonable price. There are also tourists from within and outside the country who visit the bakery as they get the information from social media and blog posts displayed at the existence of this bakery in Johor Bahru Old Town. Indirectly, information technology also promotes Salahuddin Bakery; so much that many local and foreign journalists have interviewed it. This clearly proves customer communication and support play a significant role in the continuity of a traditional family business. It is in line with Albayrak and Gunes (2010) and Muhammad et al. (2013) who contended that traditional food products would impact the society through various forms of communication, especially to traditional food products recognised by the local community. Knowledge transfer is the last factor that affects the continuation of a family traditional food business. The finding clearly shows that the role of traditional knowledge transfer cannot be ignored as one of the critical elements in the maintenance of this family bread tradition business. The use of traditional 
recipes can be maintained through food knowledge transfer to the next generation. The involvement of family members is very important in determining the retention of traditional food especially when it is commercialised. This is in line with what has been noted by The European Union (2007). Many traditional foods have long been practised and continued to sustain through knowledge transfer activities by their heirs even though their founders have passed away.

\section{Conclusion}

In conclusion, premise, products, equipment, materials, customer and knowledge transfer are essential elements in determining the sustainability of the family traditional food business for future generations. Family food traditions must be maintained and developed in line with social and technological advances. This study focuses on the continuation of the traditional family food business. The case of Salahuddin Bakery in Johor showed that it could indirectly broaden and improve the understanding and contribution of gastronomic literature to academics. This proves that the area has not been fully explored. Therefore, research on ethnic traditional gastronomic business sustainability should be given further attention.

\section{Corresponding Author}

Mohd. Shazali Md. Sharif. Department of Culinary Arts and Gastronomy, Faculty of Hotel and Tourism Management. Universiti Teknologi MARA, Kampus Puncak Alam 42300 Selangor Malaysia.

Email: shazali@uitm.edu.my

\section{References}

Albayrak, M., \& Gunes, E. (2010). Traditional foods: Interaction between local and global foods in Turkey. African Journal of Business Management, 4(4), 555-561.

Almerico, G. M. (2014). Food and identity: Food studies, cultural, and personal identity. Journal of International Business and Cultural Studies, 8, 1.

Almli, V. L., Verbeke, W., Vanhonacker, F., Næs, T., \& Hersleth, M. (2011). General image and attribute perceptions of traditional food in six European countries. Food Quality and Preference, 22(1), 129-138.

Bertozzi, L. (1998). Tipicidad alimentaria y dieta mediterra' nea. In A. Medina, F. Medina, \& G. Colesanti (Eds.), El color de la alimentacio'n mediterra'nea. Elementos sensoriales y culturales de la nutricio'n (pp. 15-41). Barcelona: Icaria.

Counihan, C., \& Esterik, P. V. (2008). Food and culture: A reader. New York: Routledge.

Counihan, C., \& Van Esterik, P. (2012). Why food? Why culture? Why now? Introduction to the third edition. In food and culture (pp. 15-30). Routledge.

Crotty, P. (2004). Food and Class. IN Germov, J. \& Williams, L.(Eds.) A sociology of food \& nutrition: the social appetite. South Melbourne.

Debevec, L., \& Tivadar, B. (2006). Making connections through foodways: contemporary issues in anthropological and sociological studies of food. Anthropological Notebooks, 12(1), 516.

Di Piazza, A., Museum, B. P. B., \& Pearthree, E. (2004). Bishop Museum Bulletins in Anthropology. London: Bishop Museum Press.

Egeland, G., Roberts, G. C., Kuluguqtuq, J., Kilabuk, J., Okalik, L., Soueida, R., \& Kuhnlein, H. (2009). Back to the future: using traditional food and knowledge to promote a healthy future among Inuit Indigenous Peoples' food systems: the many dimensions of culture, 
diversity and environment for nutrition and health. Rome: Food and Agriculture Organization of the United Nations, 109.

European Union. (2007). European Research on Traditional Foods. Belgium: Publications.europa.eu.

Gold, A. L. (2007). Changing foodways: Generational communication in a new American refugee population. (Unpublished Doctoral Dissertation). North Dakota State University.

Gutierrez, P. (1999). Cajun Foodways. Missisippi: University Press.

indentities. In A. Bower (Ed.), African American Foodways: exploration of history and culture. United States: University of Illinois Press.

Jeinie, M. H., Nor, N. M., Saad, M., Sharif, M. S. M. (2017). An ethnographic survey of culinary students' behaviours in the implementation of food safety and hygiene practices. Pertanika Journal Science \& Technology (JST), 25 (S).

Jordana, J. (2000). Traditional foods: challenges facing the European food industry. Food Research International, 33(3-4), 147-152.

Kwik, J. C. (2008). Traditional food knowledge: A case study of an Immigrant Canadian "foodscape". Environments, 36(1), 59-74.

Ma, G. (2015). Food, Eating Behaviour, and Culture in Chinese Society. Journal of Ethnic Foods 2 (2015) 195-199.

Moginon, D. F., Toh, P. S., \& Saad, M. (2012). Indigenous food and destination marketing. Current issues in hospitality and tourism: Research and innovations, 355-358.

Muhammad, R., Zahari M. S., Abdullah K. M., \& Sharif M. S. (2015). Young Generation Practices on Malaysian Ethnic Festival Foodways. Procedia-Social and Behavioral Science 170, 300-307.

Muhammad, R., Zahari, M. S., \& Sharif M. S. (2013). Impact of Technology Advancement on the Malaysian Ethnics Festival Foods and Its Foodways, Procedia-Social and Behavioral Science 101, 454-463.

O'Connor, B. (2008). Protecting tarditional knowledge: an overview of a development area of intelletual property law. The Journal of World Intellectual Peoperty, 6(5), 677-698.

Pieniak, Z., Verbeke, W., Vanhonacker, F., Guerrero, L., \& Hersleth, M. (2009). Association between traditional food consumption and motives for food choice in six European countries. Appetite, 53(1), 101-108.

Rearick, A. N. (2009). "Food is something that we gather around": Foodway practices among Arab Americans in Columbus. Ohio: The Ohio State Universiry.

Saad, M., Kamarizzaman, N. A., Ishak, N., \& Pratt, T.J. (2021). The influence of Pahang Heritage food on behavioral intentions among Malaysian domestic tourists. EnvironmentBehaviour Proceedings Journal, 6(16), 163-169.

Sharif, M. S. M., Nor, N. M., Zahari, S. M., \& Jeinie, M. H. (2017). The Malay Traditional Food Preparation. Asian Journal of Quality of Life, 2(7), 39-47.

Sharif, M. S. M., Rahman, A. E. A., Zahari, M. S. M., \& Abdullah, K. M. (2018). Malay traditional food knowledge transfer. Asian Journal of Quality of Life, 3(10), 79-88.

Sharif, M. S. M., Zahari, M. S. M., Nor, N. M., \& Muhammad, R. (2016). The importance of knowledge transmission and its relation towards the Malay traditional food practice continuity. Procedia-Social and Behavioral Sciences, 222, 567-577.

Trichopoulou, A., Soukara, S., \& Vasilopoulou, E. (2007). Traditional foods: a science and society perspective. Trends in Food Science \& Technology, 18(8), 420-427.

Trichopoulou, A., Soukara, S., \& Vasilopoulou, E. (2007). Traditional Foods: A Science and Society Perspective. Trends in Food Science \& Technology, 18(8), 420-427. 
Welch, D. P., \& Scarry, C. M. (1995). Status related variation in foodways in the Moundville Chiefdom. American Antiquity, 60(3), 397-419.

Whyte, R., Hudson, J. A., Hasell, S., Gray, M., \& O'Reilly, R. (2001). Traditional Maori food preparation methods and food safety. International Journal of Food Microbiology, 69(3), 183-190.

Williams-Forson, P. (2007). Chicken and chains: using African American foodways to understand Black

Yohannes, S. (2009). Traditional Food Consumption, Anthropometry. Nutrient Intake and the Emerging Relationship between Inuit Youth and Traditional Knowledge In Baffin Island Community. Montreal: McGill University. 